\title{
IDENTIDADES TERRITORIAIS E GLOBALIZAÇÃO: A RELAÇÃO ENTRE ESPAÇO, POLÍTICA E CULTURA NO PROCESSO DE DES-RE- TERRITORIALIZAÇÃO
}

\section{Territorial identities in the globalization: the relationship between space, policy and culture process of de-re-territorialization}

\author{
Marcos Leandro Mondardo \\ marcosmondardo@yahoo.com.br. \\ Universidade Estadual de Mato Grosso do Sul - UEMS
}

\section{Resumo}

Analisamos e discutimos aqui, a questão das identidades territoriais em curso no período da globalização a partir da década de 1970. Apontamos que no período de aceleração das trocas materiais e imateriais através da mundialização da mercadoria, ocorre, concomitantemente, a afirmação, reconstrução, reinvenção e acionamentos de identidades territoriais através da relação imbricada entre espaço, política e cultura que configura entre os diferentes sujeitos, grupos e/ou classes sociais através da mobilidade espacial e do processo de de-re-territorialização das relações sociais.

Palavras-chave: Identidades territoriais, globalização, cultura.

\section{Abstract}

We analyzed and discussed here, the issue of territorial identities in the current period of globalization from the 1970s. Point out that during the acceleration of exchanges of tangible and intangible through globalization of goods, is, accordingly, the statement, reconstruction, and drives reinvention of identity through the territorial imbricated relationship between space, politics and culture 
that sets between the different subjects, groups and/or social class mobility through space and the process of de-re-territorialization of social relations.

Key-words: Territorial identities, globalization, culture.

A construção de identidades vale-se da matéria-prima fornecida pela história, geografia, biologia, instituições produtivas e reprodutivas, pela memória coletiva e por fantasias pessoais, pelos aparatos de poder e revelações de cunho religioso. Porém, todos esses materiais são processados pelos indivíduos, grupos sociais e sociedades que reorganizam seu significado em função de tendências sociais e projetos culturais enraizados em sua estrutura social, bem como em sua fusão de tempo/espaço.

Manuel Castells

O poder da identidade

\section{Introdução}

Compreender e desvendar como a identidade é produzida/inventada, ativada e reivindicada em uma parcela referencial de espaço-tempo para dar sentido a um território, remete, primeiramente, à incursão sobre conceito de identidade e como esta se liga ao território e as mudanças na relação do sujeito com a base territorial (o território) no presente período da globalização. Por isso, apontaremos algumas questões em que a identidade tem sido discutida, na Geografia, pois emerge o interesse cada vez maior pelos estudos referentes às identidades regionais e/ou territoriais, mas, também, buscaremos compreender as identidades através da Sociologia e das Ciências Sociais em geral. 


\section{Globalização e identificações em curso nos territórios}

As discussões sobre a questão da identidade são complexas e polêmicas, já que o conceito é portador de ambigüidades teóricas e políticas. Stuart Hall (2007) afirma que só é possível estudá-lo sob "rasura", ou seja, sob uma perspectiva em que - apesar de demonstrar sua precariedade ou imprecisão explicativa - o conceito de identidade comporta algo de "irredutível", que está no intervalo e na emergência de uma idéia que não pode ser pensada de forma "antiga" e que, sem a qual, certas questões não podem ser pensadas/analisadas. Desse modo, a identidade não pode mais ser entendida enquanto relacionada exclusivamente ao Estado-Nação, pois esta relação é muito restrita ao potencial de compreensão nos estudos culturais e políticos, especialmente.

A partir destas transformações que ocorreram na sociedade e, por extensão, nas Ciências Sociais, Stuart Hall (2004, pp. 10-13) apresenta três concepções de identidade que alternaram sua significância/significado na sociedade através do tempo e do espaço. São elas, a do:

a) sujeito do Iluminismo: baseava-se na concepção de pessoa humana como indivíduo "centrado totalmente", "unificado" e dotado das capacidades da razão, de consciência e de ação, sendo que seu "centro" era formado num núcleo interior, emergindo pela primeira vez quando o sujeito nascia e com ele se desenvolvia, permanecendo o mesmo "linear" e "idêntico" ao longo da existência do sujeito;

b) sujeito sociológico: era concebido pela crescente complexidade do mundo moderno, sendo construída na consciência interior do sujeito que não era autônomo e nem auto-suficiente, mas sim formando na relação com "outras pessoas importantes para ele", que mediavam para este os sentidos, os símbolos e os valores, ou seja, a cultura dos mundos que ele/a habitava. A identidade, nessa concepção, costura e entrelaça o 
sujeito à estrutura, estabilizando os sujeitos e os "mundos culturais" em que habitam, de forma recíproca e unificada;

c) sujeito pós-moderno: aponta-se que esse sujeito está se tornando "fragmentado", composto não mais de uma única identidade mas de várias, podendo ser identidades contraditórias ou não-resolvidas. Resultado de mudanças estruturais e institucionais, a identidade não é mais "fixa", "unificada", "essencial", mas variável, provisória e problemática. A identidade se torna uma "celebração móvel", constituída, continuamente, em relação às formas que somos representados ou nos deparamos em sistemas culturais múltiplos que nos rodeiam.

Neste contexto, no período que, de acordo com Hall, antecede à era moderna, as diferenças eram toleradas e até mesmo valorizadas, na medida em que se procurava torná-las aparentes. Trata-se da concepção da identidade do sujeito do lluminismo.

Com a emergência e estabelecimento da modernidade, cujos fundamentos principais são a separação entre aparência e essência, sujeito e objeto, objetivo e subjetivo, racional e irracional e o científico e o não-científico, haveria, o pressuposto da "eliminação" e/ou supressão da diferença nas análises e, a conseqüente transformação na concepção de identidade do sujeito. De acordo com Moreira (1999), em conformidade com tal proposição, pode-se associar esse método da modernidade baseado, sobretudo, na razão, onde ocorre a supressão da diferença, ou seja, busca-se suprimir o que é singular, o que é particular, sendo que, desta forma, ocorre "uma co-habitação tensa da diferença e da unidade" (p. 44).

A concepção de identidade do "sujeito do Iluminismo" desliza dando "lugar" para o conceito de identidade do "sujeito sociológico", frente às complexas transformações ocorridas/estabelecidas no mundo moderno. 0 sujeito sociológico, enfim, foi tomado de forma monolítica, subjugando diferenças, ignorando o mencionado abismo entre indivíduo e sociedade. Assim, o conflito entre parte e todo se tornou latente e insolúvel. 
Entretanto, a modernidade e suas correspondestes metanarrativas, reivindicando explicações totalizantes nas Ciências Sociais, parece ter se tornando vencedora, posto que o paradigma cartesiano se impõe como dominante. Como caracterização de identidade do sujeito, ressalta-se que podia ser considerada monolítica, imutável, estável e determinada pelo contexto social da modernidade, tendo como seu agente correlato a nação, como "comunidade imaginada" (WOODWARD, 2007).

A globalização, tomada como movimento homogeneizador, fez com que se reforçasse um discurso oposto, o da diferença. A nossa experiência espaçotemporal, parecendo solidamente determinada, "desmanchou-se no ar", fragmentando os sujeitos e suas respectivas identidades, criando a identidade do sujeito pós-moderno. Paradoxalmente, segundo Castells (1999a, p. 85), ocorre, também, aliado a essa fragmentação das identidades, uma busca maior por pertencer a um grupo, a algum lugar. Para o autor, "quando o mundo se torna grande demais para ser controlado, os atores sociais passam a ter como objetivo fazê-lo retornar ao tamanho compatível com o que podem conceber" e, por isso, "quando as redes dissolvem o tempo e o espaço, as pessoas se agarram a espaços físicos, recorrendo à sua memória histórica".

Nesse sentido, para Hall (2004), esse processo de fragmentação das identidades:

(...) solapa a idéia da nação como cultura unificada. As unidades nacionais não subordinam todas as outras formas de diferenças e não estão livres do jogo do poder, de divisões e contradições internas, de lealdades e de diferenças sobrepostas. Devemos ter em mente a forma pela qual as culturas nacionais contribuem para "costurar" as diferenças numa única identidade (p. 65).

Após os anos 1970, tanto o alcance quanto o ritmo da integração global aumentaram enormemente, acelerando os fluxos e os "laços" entre as nações. Com o processo social pelo qual os fenômenos se aceleram e se difundem pelo globo, compreendido enquanto "compressão espaço-tempo" (HARVEY, 
1994), e com a emergência da "sociedade em rede" (CASTELLS, 1999b), as identidades culturais passaram por profundas transformações.

Aliado a isso, Bauman (2005) vê a globalização como uma forma de mudança radical e irreversível. Para o autor, ocorre uma "grande transformação" que afetou as estruturas estatais, as condições de trabalho, as relações entre os Estados, a subjetividade coletiva, a produção cultural, a vida cotidiana e as relações entre o eu e o outro.

A partir dessas transformações, Hall (2004, p. 69) aponta a coexistência dos seguintes processos identitários:

- As identidades nacionais estão se desintegrando, como resultado do crescimento da homogeneização cultural e do "pós-moderno global";

- As identidades nacionais e outras identidades "locais" ou particularistas estão sendo reforçadas pela resistência à globalização; e,

- As identidades nacionais estão em declínio, mas novas identidades híbridas - estão tomando seu lugar (grifos do autor).

O impacto da globalização sobre a identidade se dá porque se altera a forma com que o tempo e o espaço, como coordenadas de sistemas de representação, são relacionados com os processos sociais. Para Hall (2004), diferentes épocas culturais têm diferentes formas de combinar essas coordenadas espaço-tempo e, portanto, as formas de representação da relação identitária e, poderíamos acrescentar, com a construção da identidade referente a uma parcela de espaço-tempo.

Isso posto, sobre as transformações que estão ocorrendo com as identidades, gostaríamos de passar a analisar agora alguns aspectos que consideramos fundamentais para o entendimento da identidade, sobretudo para nosso recorte espacial. Assim, partimos do pressuposto de que a identidade territorial é construída discursivamente no e através de um recorte espacial; é uma construção demarcada a partir de um recorte territorial onde se estabelecem relações. A identidade territorial é definida a partir de um território ou, num sentido mais amplo, a uma formação do espaço geográfico. 
Entretanto, pode-se afirmar, de acordo com Haesbaert (2007, p. 44), que "como toda relação social, toda identidade cultural é 'espacial', na medida em que se realiza no/através do espaço, pelo referente espacial em estratégias de apropriação, culturais e políticas, dos grupos sociais", ou seja, que mantêm o "elo entre espaço, política e cultura".

Woodward (2007, p. 13-14) afirma que a conceituação de identidade precisa ser decomposta "em suas diferentes dimensões", e envolve sistemas classificatórios "que mostram como as relações sociais são organizadas e divididas", por exemplo, pela oposição em, pelo menos, dois grupos: "nós" e "eles". Uma destas dimensões é a relativa ao sentimento de pertencimento ou não do sujeito a determinado grupo identitário, que pode ter como critério o sexo, a raça e o parentesco, ou, quando a história do passado, de um determinado território é apresentado, discursivamente, como "imutável", ou seja, se apresenta enquanto construção identitária "imutável" para mobilizar um consentimento e/ou ação. Isso pode ser verificado, por exemplo, através das tradições. Nessa perspectiva:

As identidades são fabricadas por meio da marcação da diferença. Essa marcação da diferença ocorre tanto por meio de sistemas simbólicos de representação quanto por meio de formas de exclusão social. As identidades, pois, não é o oposto da diferença: a identidade depende da diferença. Nas relações sociais, essas formas de diferença - a simbólica e a social - são estabelecidas, ao menos em parte, por meio de sistemas classificatórios. Um sistema classificatório aplica um princípio de diferença a uma população de uma forma tal que seja capaz de dividi-la (a todas as suas características) em ao menos dois grupos opostos - nós/eles (WOODWARD, 2007, p. 39-40, [grifos da autora]).

A autora nos diz ainda que a identidade é relacional, como se nascesse da diferença (que pode ser encoberta ou enaltecida), a partir de uma marca simbólica (de distinção ${ }^{2}$ ), como, por exemplo, pelo discurso, por um monumento, pela linguagem etc. A identidade está associada a condições 
materiais, onde, por exemplo, um grupo pode diferir de outro pelos recursos disponíveis que, por sua vez, determinam marcas simbólicas e sociais, delimitando as fronteiras entre exclusão e inclusão e "é por meio da diferenciação social que essas classificações da diferença são 'vividas' nas relações sociais" (WOODWARD, 2007, p. 13).

Desse modo, acrescenta a autora, as identidades "não são nunca unificadas", o que pressupõe a sua negociação (2007, p. 14). Um exemplo, relacionado à migração, é que um mesmo indivíduo, num recorte territorial é baiano, noutro recorte é nordestino e, ao mesmo tempo, é brasileiro. Ou seja, em diferentes relações (ou escalas) há diferentes partilhas de identidades, dependendo da situação, do grupo social e dos contextos na qual o sujeito esteja inserido. E, finalmente, como conseqüência dessas negociações, o sujeito assume/aciona diferentes posições de identidade e se identifica com elas.

O sociólogo Roberto Damatta (2004) também afirma que a construção das identidades implica relações. Para o autor, qualquer identidade, mesmo aquelas que se definem como "individuais", realiza-se por referências internas e externas, por meio de comparações com outras comunidades que se situam no seu âmbito histórico-geográfico. As identidades, assim, internas e externas, são "buriladas, acentuadas, negadas, construídas ou inibidas em situações de contato que agenciam a comparação e a reflexibilidade - a mais profunda e perturbadora alteridade" (p. 20). A identidade se faz num jogo relacional "entre o que deve ser necessariamente lembrado e o que deve ser necessariamente esquecido em certas situações" (p. 24).

As identidades, desse modo, são construções discursivas, como as narrativas, e servem para enaltecer determinado contexto e relação e encobrir outras relações e contextos. Por isso, Damatta (2004) afirma que nenhuma identidade é fixa, imutável, permanente e dada por essência, embora elas apareçam desse modo no senso comum, pois, aí esta a sua força, ou seja, a capacidade de "naturalização" das relações para um devido fim. 
Também, sobre o caráter relacional das identidades e o jogo entre inúmeras escalas, que é de suma importância na migração, Damatta nos dá o seguinte exemplo:

Tomemos como exemplo dessa segmentação-estruturante o tema nacional e o regional. Num dado nível, as regiões são importantes e um gaúcho pode se distinguir radicalmente de um catarinense ("barriga verde"); mas se ambos - o gaúcho e o catarinense - vão para Belém, os dois se juntam como "sulistas" em oposição aos "nortistas". Mas se um gaúcho, um catarinense e um paraense se encontram em Buenos Aires, eles imediatamente se definem como "brasileiros", por oposição aos argentinos [vistos como "gringos"]. Agora, se um argentino e esses três brasileiros se encontram em Chicago, eles invocam sua identidade de "latino-americanos", em oposição à cultura local: ianque, individualista monoglota, provinciana, etc. Nesse nível, então, o "nacional brasileiro" e o "nacional argentino" se regionalizam. (...) E isso não é tudo, pois se um americano, um argentino e três brasileiros se encontram em Paris ou Berlim, eles agora podem ser englobados pela identidade de "americanos", por contraste com uma identidade "européia". Finalmente, se um francês, um americano, um argentino e três brasileiros se encontram em Tóquio ou em Calcutá, na Índia, eles se transformam em "ocidentais" por oposição aos "orientais" (DAMATTA, 2004, p. 25).

A identidade, deste modo, se apresenta como algo relacional e escalar. Através da relação entre o nacional e o regional emerge a forma de identidade que se chama de "regional". Esta é, segundo Damatta, agenciada por disputas políticas - não apenas no sentido que a disputa faça surgir a identidade - mas, também, porque a identidade é acionada, burilada e percebida dentro de uma situação com conseqüências práticas e concretas.

Para Bhabha (1998), a identidade é "fixada" (parcialmente) através da diferença, em um processo deslizante de significados e posições de sujeito. Para ocorrer a identificação, a identidade nunca será um a priori e nem um 
produto terminado. A identidade é, para o autor, um processo problemático de acesso e constituição de uma "imagem da totalidade". Através de condições discursivas, essa imagem psíquica da identificação é construída enquanto representação, que é a marca de uma diferença, mas também é lugar de uma ambivalência, pois "sua representação é sempre espacialmente fendida - ela torna presente algo que está ausente - e temporalmente adiada: é a representação de um tempo que está sempre em outro lugar, uma repetição" (p. 85, [grifos do autor]).

Assim, as reivindicações e/ou acionamentos de identidade são, para Bhabha (1998, p. 322), nominativas e normativas em um determinado momento, que é preliminar e passageiro. As identidades nunca são produções historicamente progressivas com os mesmos conteúdos; mudam seus discursos através do tempo e no espaço de acordo com a situação, a intencionalidade e o interesse. As formas de identidade social, portanto, "devem ser capazes de surgir dentro-e-como a diferença de um-outro", assumindo o significado de tradução cultural, ou seja, jogam com a diferença do outro constituindo um ato de tradução do outro e de si mesmo.

Para Hall (2003), a identidade é eminentemente uma questão histórica. Para o autor, a maioria dos sujeitos que estão em um lugar hoje, pertenciam, originalmente, a outro. Por isso, longe de constituir uma continuidade com o nosso passado, nossa relação com a história é marcada pelas rupturas, pelos silêncios, que são muitas vezes aterradores, violentos e abruptos.

Assim, as identidades parecem reinvidicar para suas práticas discursivas, suas construções e classificações, uma origem que residiria em um passado histórico com o qual elas continuariam a manter uma certa correspondência, quando necessário, para um acionamento de determinados atributos. Hall (2007, p. 108) alude que as identidades se utilizam dos recursos da história, da linguagem e da cultura para a produção "não daquilo que nós somos, mas daquilo do qual nos tornamos". Por isso, a identidade tem a ver não tanto com as questões "quem nós somos" ou "de onde nós viemos", mas muito mais com as questões "quem nós podemos nos tomar", "como nós temos sido representados" e "como essa representação afeta a forma como nós 
podemos representar a nós próprios". Entretanto, não há um "retorno às raízes", mas uma negociação com nossas "rotas".

As identidades, portanto, surgem de uma narrativa "ficcional", mas que não diminui no processo sua eficácia discursiva material, simbólica e política, mesmo que essas identidades sejam apenas construídas pelo imaginário e, portanto, em parte, construída a partir de alguma fantasia e/ou invenção, esta terá eficácia na relação de pertencimento. Nesse sentido, o discurso toma centralidade importante para a produção da identidade. Para Hall (2007, p. 119), "o sujeito é produzido 'como um efeito' do discurso e no discurso, no interior de formações discursivas específicas, não tendo qualquer existência própria". O discurso aciona a identidade através da posição-de-sujeito, ou seja, a posição que os sujeitos assumem entre a divisão: entre o nós e o eles; entre o eu e o outro.

Portanto, as identidades são construídas através do discurso e são produzidas em locais históricos e institucionais específicos, pois:

(...) as identidades são construídas dentro e não fora do discurso que nós precisamos compreendê-las como produzidas em locais históricos e institucionais específicos, no interior de formações e práticas discursivas específicas, por estratégias e iniciativas específicas. Além disso, elas emergem no interior do jogo de modalidades específicas de poder e são, assim, mais o produto da marcação da diferença e da exclusão do que o signo de uma unidade idêntica, naturalmente constituída, de uma "identidade" em seu significado tradicional - isto é, uma mesmidade que tudo inclui, uma identidade sem costuras, inteiriça, sem diferenciação interna (HALL, 2007, p. 109, [grifos nossos]).

Hall (2007) afirma ainda que, essencialmente, presume-se que a identidade cultural seja fixada no nascimento do sujeito, seja parte da natureza socialmente transformada (ou seja, da paisagem), impressa através do parentesco e da linhagem dos genes e seja parte constitutiva de nosso eu mais 
interior pressupondo uma construção subjetiva. Entretanto, essa construção, mesmo subjetiva, lida com aspectos materiais e simbólicos. ${ }^{3}$

Para Castells (1999a), a identidade é uma construção histórica dos significados sociais e culturais que referenciam o processo de distinção e identificação de um indivíduo ou de um grupo. As identidades, para o autor, são construídas culturalmente e organizadas em torno de um conjunto específico de valores, cujo significado e uso compartilhado "são marcados por códigos específicos de auto-identificação, a comunidade de fiéis, os ícones do nacionalismo, a geografia do local” (p. 84). Por isso, assim como a construção discursiva das identidades para Castells não é arbitrária, ela depende da forma como é trabalhada e re-significada a "matéria-prima fornecida pela história, geografia, língua e ambiente". Assim, as identidades são construídas discursivamente, tanto material quanto simbolicamente, em torno de reações e projetos políticos determinados por fatores históricos e geográficos.

A identidade é construída a partir de significados, que criam identificação com a prática social simbólica que é discursivamente conduzida por parte de um ator social, que dá finalidade a uma ação prática. Essa ação que pode, entre outras coisas, criar o sentimento de pertencimento de um indivíduo a um grupo social e a um recorte espacial.

A eficácia das estratégias identitárias irá depender do poder de mobilização e de legitimação. Contudo, isso irá depender do capital econômico, político e, em especial, do capital simbólico que se possui na estrutura de determinado recorte espacial e na estrutura de um grupo social. É através da afirmação do poder de "autoridade legítima" e do poder simbólico que, pela força do "discurso performático", do poder quase mágico das palavras, das imagens, dos símbolos, dos cortes e recortes da historicidade local, dos enunciados escolhidos e da repetição induzida por estes, que a identidade pode produzir o consenso, a mobilização e a ação.

Através do "discurso performático", de acordo com Silva (2007), as identidades buscam ser completamente unificadas, estáveis, fixas, únicas; entretanto, o mesmo "discurso performático" que repetidamente tende a fixar e a estabilizar uma identidade, silenciando outras, pode, também, subvertê-la, 
desestabilizando-a, ou seja, o que está na "margem" pode se tornar o "centro". Assim, esse discurso pode desqualificar o outro e, por extensão, a outra identidade, buscando tornar-se uma identidade hegemônica.

Assim, a identidade é uma constante disputa pelo poder, como aponta Bauman (2005). É uma luta, uma guerra discursiva e legitimadora de um consenso, de uma "naturalização" das relações. As identidades são construídas no interior das relações de poder, nas disputas, nos campos de força entre a legitimação e a não legitimação, entre a identidade hegemônica e a identidade subalterna, num jogo de anunciação e aceitação da "verdade" historicamente construída.

Nesse sentido, a identidade está eminentemente dentro de um campo de disputa pelo poder:

As identidades, portanto, são construídas no interior das relações de poder (Foucault). Toda identidade é fundada sobre uma exclusão e, nesse sentido, é "um efeito do poder". Deve haver algo "exterior" a uma identidade (...). Esse "exterior" é constituído por todos os outros termos do sistema, cuja "ausência" ou falta é constitutiva de sua "presença" (...). Sou um sujeito precisamente porque não posso ser uma consciência absoluta, porque algo constitutivamente estranho me confronta. Cada identidade, portanto, é radicalmente insuficiente em termos de seus "outros" (HALL, 2003, p. 85, [grifos do autor]).

Neste contexto, para Silva (2007), a identidade tal como a diferença é uma relação social. Isso porque a capacidade de definir e/ou classificar discursivamente está inserida em um campo como vetores de força, ou seja, com as relações de poder, de luta e disputa. Essas relações não convivem harmoniosamente uma ao lado da outra, em um campo sem hierarquias: são disputadas e impostas. A identidade e a diferença estão em estreita conexão com relações de poder, pois "o poder de definir a identidade e de marcar a diferença não pode ser separado das relações mais amplas de poder. A identidade e a diferença não são, nunca, inocentes" (SILVA, 2007, p. 81). 
A afirmação da identidade e a demarcação da diferença implicam, necessariamente, em operações de incluir e de excluir. Por isso, a identidade está sempre relacionada a uma forte separação entre "nós" e "eles". Essa demarcação de fronteiras, essa separação, está ligada às classificações e às distinções. Segundo Silva (2007, p. 82), a separação entre "nós" e "eles" não são simples categorias gramaticais, mas "evidentes indicadores de posiçõesde-sujeito fortemente marcadas por relações de poder". Assim, pode-se dizer que:

(...) onde existe diferenciação - ou seja, identidade e diferença - aí está presente o poder. A diferenciação é o processo central pelo qual a identidade e a diferença são produzidas. (...) São outras tantas marcas da presença do poder: incluir/excluir ("estes pertencem, aqueles não"); demarcar fronteiras ("nós" e "eles"); classificar ("bons e maus"; "puros e impuros"; "desenvolvidos e primitivos"; "racionais e irracionais"); normalizar ("nós somos normais; eles são anormais") (SILVA, 2007, p. 81-82).

Nesse sentido, a identidade é construída a partir de recursos simbólicos que são utilizados e acionados para mobilizar o sentimento de pertencimento, a ação e o "consenso". Há mobilizações discursivas assim como de recursos simbólicos para forjar a identidade cultural (e "política"), como, por exemplo, a identidade nacional, que contribuem para ativar o sentimento de pertencimento. Dentre os principais recursos destacamos o mito fundador (CHAUÍ, 2006), a invenção das tradições (HOBSBAWM \& RANGER, 1997), a narrativa da nação e a memória, que dão forma ao que Said (apud HALL, 2004) chama de "geografias imaginárias".

O mito fundador, segundo Chauí (2006), oferece um repertório construído enquanto "inicial" de representações da realidade em um determinado lugar, e em cada momento da formação histórica "esses elementos são reorganizados tanto do ponto de vista de sua hierarquia interna (isto é, qual o elemento 
principal que comanda os outros) como da ampliação de seu sentido (isto é, novos elementos vêm se acrescentar ao significado primitivo)" (p. 9).

Para a autora, as ideologias acompanham e/ou são formadas concomitantemente com o movimento histórico da formação de uma nação, por exemplo, alimentando-se das representações produzidas pelo mito fundador, atualizando-se e se adequando à renovação da sociedade. Por isso, o mito pode repertir-se indefinidamente no desenrolar da história, sobre nova "roupagem", assumindo novas "faces" que são re-produzidas constantemente pelo discurso, pois "Um mito fundador é aquele que não cessa de encontrar novos meios para exprimir-se, novas linguagens, novos valores e idéias, de tal modo que, quanto mais parece ser outra coisa, tanto mais é a repetição de si mesmo" (CHAUí, 2006, p. 8, [grifos totais da autora]).

Aliado a isso, para Hall (2003), os mitos fundadores são transitórios; estão fora da história e, por isso, são fundamentalmente a-históricos. Sua estrutura tem dupla inscrição: se por um lado seu poder redentor encontra-se no futuro que está por vir, por outro lado, funcionam atribuindo o que predizem à sua descrição do que já aconteceu, do que "era no princípio". Assim, a estrutura narrativa dos mitos é cíclica, ou seja, vai e volta, é acionada ou não, o que implica, na história e na geografia, que seu significado seja freqüentemente transformado, adaptado, dependendo do contexto e do resultado que se quer atingir.

Quanto às "tradições inventadas", Hobsbawm (1997, p. 9) afirma que muitas vezes as "tradições" que aparecem ou são consideradas antigas e/ou tradicionais, são na verdade bastante recentes, quando não inventadas. As "tradições inventadas" são reações a situações novas que ou assumem a forma de referência a situações e contextos anteriores em um lugar, ou estabelecem seu próprio passado através da repetição quase que obrigatória para sua manutenção. Essas "tradições inventadas" aparecem como contraste entre as constantes mudanças e inovações do mundo moderno e se constituem como uma tentativa de estruturar-se de maneira "imutável" e "invariável", ao menos em alguns aspectos da vida social (como, por exemplo, os rituais, as festas etc., mas, também os comportamentos, as regras, os modos de ver, sentir e comportar-se etc.), tornando-se "invenções" ligadas a 
um passado distante que, como apresentado, podem nunca ter existido daquela maneira como é expressa, como é "inventada".

Hobsbawm (1997, p. 13) considera, portanto que a "invenção de tradições" é essencialmente um processo de "formalização e ritualização", caracterizado, por referir-se ao passado, "mesmo que apenas pela imposição da repetição". Nesse sentido, por “tradição inventada' entende-se um conjunto de práticas, normalmente reguladas por regras tácita ou abertamente aceitas" (1997, p. 9).

Outro elemento importante na construção da identidade cultural se refere às estratégias discursivas de narrativa ligadas a cultura nacional e, num sentido mais restrito, de um recorte espacial como um estado ou município etc. Para Hall (2004), a narrativa da nação, tal como é contada e recontada nas histórias e nas literaturas "oficiais", na mídia e na cultura popular fornecem discursivos que contêm uma série de estórias, imagens, panoramas, cenários, eventos históricos, símbolos e rituais que representam o compartilhamento de experiências: de perdas, de alegrias, de vitórias, de derrotas, de silêncios e de gritos etc. ${ }^{4}$ Assim, podemos dizer que membros de um recorte espacial compartilham, em alguma medida, de uma narrativa que simboliza e materializa uma relação e, com isso, um (con)sentimento (o que não impede, entretanto, que haja resistência, pois, como afirma Michel Foucault [1985], onde há poder há resistência).

Também, para Hall (2004), a narrativa é construída a partir e na ênfase das origens de determinado grupo social. A identidade, nesse sentido, é "representada por 'coisas' que estão sempre lá, estão 'adormecidas' mas podem ser 'acordadas' a qualquer momento" (p. 56). Por isso, para o autor, os elementos e/ou a carga simbólica que participa dessa narrativa permanecem como "imutáveis", apesar de todas as descontinuidades da história e, portanto, da geografia. Essa narração é construída e se apresenta a partir da história "oficial" do "nascimento" enquanto "unificada", "imutável", "eterna" ao longo das transformações da sociedade, das descontinuidades, das rupturas etc. Assim, tem-se a idéia construída simbolicamente, segundo Hall, de povo "original", "pioneiro", "puro", "superior", com suas práticas que são "únicas" e com 
qualidades que são "especiais", "acima” de quaisquer espaço(s)-tempo(s) outro(s). Entretanto, na realidade, na dura realidade vivida, raramente é o povo "especial" e "único" que exercita o poder da sociedade, o poder de controlar, de "viver bem" etc.

A narração é, portanto, um discurso que mascara e encobre viveres e saberes que se quer homogêneo, que deturpa as "qualidades" e os "defeitos" de um povo, de um grupo social. São construções que servem para encobrir, para generalizar, para subverter a realidade em prol de alguns, ou seja, dos detentores do poder hegemônico local, regional e/ou nacional. A narrativa é uma construção discursiva dentro de um campo de poder, de um campo daqueles que exercem o poder sobre determinado contexto, situações e relações, sobre e em um território.

Outro recurso simbólico para o acionamento da identidade é a memória. Para Mendes (2005), com a multiplicação das opções de relações e de contatos com a globalização, "ocorre em simultâneo, e em aparente contradição, um tempo de localismos, territorializações de identidade, de singularidades, de genealogias e de memórias" (p. 513).

Por isso, para o autor, a temática das identidades se cruza com a questão da produção e perpetuação das memórias sociais. "Estas, para serem eficazes, têm que ser celebradas e comemoradas". Papel relevante, portanto, cabe aos mediadores, aos empresários da memória (na concepção de Michel Pollack [1992]), que num trabalho identitário constante procuram reiterar as "certezas adquiridas", os "axiomas", "fixar" e "cristalizar" e/ou adaptar a tradição, contra o efeito perturbador e desafiador do "acaso" e dos “imprevistos". Para Mendes (2005, pp. 513-514), os mediadores da memória procuram impossibilitar o pensar de alternativas, fechar o campo celebratório. Na solidificação das memórias, essencial é a possibilidade de simbolização e da sua reprodução ritualística. As identidades, nesse sentido, se ligam ao "discurso performático", um discurso que é ativado e que se aplica no cotidiano em uma fusão parcial na coletividade e na comunidade, ou seja, em um território. 
Assim, a memória é um elemento fundamental na apreensão da construção e desconstrução das identidades. Como afirma Pollak (1992, p. 2004), "a memória é um elemento constituinte do sentimento de identidade, tanto individual quanto coletiva". Para Mendes (2005, pp. 514-515), a memória é marcada pela descrição e pelos predicados que buscam uma qualificação ou não dos acontecimentos e traços que deixou. Para o autor, através do estudo da memória temos um melhor acesso ao sentido de certos acontecimentos, uma verdade subjetiva e não-referencial a uma "história oficial", "colonizada". Busca-se o desvendamento, a "escavação" que permite conhecer no interior de um grupo e no seu contexto as experiências dos que detém as ideologias e/ou discursos opostos, ou seja, chegar até as contradições, os conflitos, as relações.

Mas também, para $\circ$ autor, $\circ$ estudo da identidade não deve desconsiderar ou ir em oposição à "história oficial", mas sim, estabelecer uma relação de complemetariedade. À "verdade" construída pela "história oficial" deve se acrescentar a "verdade" de desvendamento característica da memória. Com isso, o interessante é compreender como que as pessoas utilizam a memória e a cultura como um tema para reivindicarem, descartarem, imputarem ou resistirem a relações particulares e específicas de um determinado contexto de enunciação, de um determinado espaço de relação.

É importante afirmar, contudo, que a memória não existe sem a mediação/referência/relação com o espaço e o tempo. De acordo com Halbwachs (2006), a memória é enfatizada a partir da inseparabilidade entre o tempo e o espaço, como um conjunto de lembranças construídas socialmente e referenciadas no espaço-tempo. Por isso, toda memória coletiva ${ }^{5}$ tem como "suporte um grupo limitado no tempo e no espaço" (p. 106) e, por isso, não pode haver memória coletiva "que não se desenvolva num quadro espacial" ( $p$. 164).

Desse modo, segundo Mendes (2005), as identidades emergem da narrativização do sujeito (ou de um grupo) e das suas vivências sociais, buscando não deixar que a natureza necessariamente ficcional deste processo afete na eficácia discursiva, material ou política da construção e "manutenção" 
das mesmas. Nesse sentido, "as identidades constroem-se no e pelo discurso, em lugares históricos e institucionais específicos, em formações práticodiscursivas específicas e por estratégicas enunciativas precisas" (p. 505).

No entanto, as identidades também contêm o seu reverso e aí reside a importância da relação e do desvendamento da memória dos sujeitos. Todas as sociedades, grupos e classes sociais produzem memórias subterrâneas, escondidas, silenciadas, camufladas, esquecidas no "discurso performático" que enaltece umas e encobre outras relações. Por isso, para Mendes (2005, p. 506), é imprescindível que se privilegie na análise "os espaços onde exista conflito e competição entre memórias concorrentes", pois as "memórias subterrâneas constituiem-se e reproduzem-se em redes sociais informais, cabendo verificar como se relacionam com as memórias oficiais e quais as condições materiais, sociais e simbólicas para se reproduzirem".

Assim, Mendes (2005), baseado em Stuart Hall, ressalta que a identidade funciona como articulador e como ponto de ligação entre os discursos e as práticas sociais. Os discursos buscam interpelar, falar, impor e produzir os sujeitos de um lugar com relações características singulares, distintivas, particulares; esses discursos produzem a subjetividade que constrói os sujeitos que podem falar e ser falados.

Ademais, para o autor, as identidades são ativadas estrategicamente pelas contingências, pelas lutas, sendo permanentemente reconstruídas na ação. Assim, as práticas identitárias são relacionais e múltiplas, baseadas na diferenciação e na identificação que são sempre situacionais, históricos e geográficos, havendo em cada período de espaço-tempo expressões, discursos, narrativas, estratégias e/ou práticas identitárias que são hegemônicas, dominantes. Essa permanência identitária hegemônica é elaborada pela narrativa, dentro de discursos ativados em contextos singulares. Também, a questão do poder e da desigualdade no processo identitário devem ser analisados, pois "a posição no espaço social, o capital simbólico de quem diz o quê, condiciona a construção, legitimação, apresentação e manutenção das identidades" (MENDES, 2005, p. 505). 
Uma perspectiva eminentemente geográfica, para entender a questão das identidades, é a proposição feita por Haesbaert (1999), de que determinadas identidades são construídas a partir da relação concreta/simbólica e material/imaginária dos grupos sociais com o território. Estas seriam identidades territoriais por serem construídas pelo processo de territorialização. O território enquanto processo se realiza por um sistema de classificação que é ao mesmo tempo funcional e simbólico, incluindo e excluindo por suas fronteiras, (re)forçando as des-igualdades sociais e as diferenças culturais entre indivíduos e/ou grupos sociais. Assim, o processo de territorialização, seja pela funcionalização (domínio) ou pela simbolização (apropriação), ou pela combinação simultânea desses dois movimentos, constrói diferenças, alteridades e identidades. De acordo com o autor, cada território se constrói por uma combinação e imbricação única de múltiplas relações de poder, do mais material e funcional, ligado a interesses econômicos e políticos, ao poder mais simbólico e expressivo e às relações de ordem mais estritamente cultural.

A identidade está relacionada a pessoas e objetos, em situação de semelhança ou de desigualdade. Por isso, para o autor (talvez) o maior paradoxo seja encontrar a diferença e igualdade num "objeto" ou "pessoa", ou seja, buscar aquilo que é singular, "único", com o geral, com a totalidade, apreendendo o significado específico e geral. Também, a identidade individual e/ou social está carregada, ao mesmo tempo, de subjetividade e de objetividade, pois, "por mais que se reconstrua simbolicamente um espaço, sua dimensão mais concreta constitui, de alguma forma, um componente estruturador da identidade" (HAESBAERT, 1999, p. 174, [grifos do autor]).

Nesse âmbito, para compreendermos como que a identidade social é através da mediação do espaço, identidade territorial, segundo Haesbaert, é importante a atuação do símbolo, ou, se quisermos, do poder simbólico. Por isso, para o autor, os símbolos contêm e mantêm uma relação direta com a nomeação (ou poder de nomear as coisas e as pessoas), que é carregado de subjetividade; o símbolo tem a capacidade de criar sentidos, indiretos, secundários e, até mesmo, inesperados; a identidade social, desse modo, é 
mobilizada e mobiliza um poder simbólico (tal como definiu Bourdieu [1998]) que se desdobra e é espaço. O símbolo é alocado em ponto estratégico e referencial do espaço, que atua como constructo fundamental do poder simbólico.

Contudo, nos símbolos, haveria sempre um deslocamento de sentido, nunca de todo definido ou explicado; esse "deslizamento" de sentido, de acordo com Haesbaert (2001a), nunca pode ser total e o símbolo precisa sempre de algum referente concreto e espacial para se realizar. Este referente, por exemplo, pode ser um recorte ou uma característica espacial através de uma di-visão geográfica; neste caso, podemos ter a construção de uma identidade pelo/com o território, ou seja, construindo aquilo que o autor chama de identidade territorial.

Nessa perspectiva, o poder simbólico constrói a identidade através de sua eficácia em "naturalizar" a ação, a mobilização e o "(con)sentimento" sobre (e em) um território; é o poder que constrói a identidade territorial pela eficácia da "naturalização" das relações, tornando a identidade um elemento puramente "objetivo", "dado", mas que, no entanto, é permeado de subjetividade. Essa construção, segundo Haesbaert (1999), transforma a complexidade do poder simbólico e sua trama territorial no "simplismo" de uma "construção natural", ahistórica e aparentemente imóvel, pois "seu poder, assim, é muitas vezes mais forte e eficaz do que o poder 'objetivo', mais concreto, porque o poder simbólico é mais sutil em suas formas de manifestação e, portanto, mais dificilmente reconhecido" (p. 178).

Assim, as identidades são construções ancoradas/produzidas em determinados referenciais de espaço-tempo, ganhando aparência de "concretude" pela "naturalização" de sua existência e atuação. Desse modo, segundo Haesbaert (2007), as identidades, em seu caráter múltiplo e relacional, são sempre re-configuradas tanto em relação ao passado, aliando memória e/ou imaginação (poderíamos dizer, também, aqui, invenção), portanto, aliados à dimensão história, produzem o presente apontando o futuro, do qual se utilizam do entorno e dos contornos espaciais dos quais são vividos, 
vivenciados, experienciados, "comidos", "roídos", recorrendo, também, à dimensão geográfica, sócio-espacial.

A identidade, nesse sentido, cria e re-cria espaços de referência identitária. Esse referente espacial é produzido tanto concreta como simbolicamente, onde se produz e se ancora determinada cultura que é, em alguma medida, também política. Refere-se, portanto, ao recorte espaçotemporal das relações onde se realiza, simbólica e materialmente a experiência social, política e cultural. É nele que são mobilizadas as práticas materiais (formas de uso, produção e organização do espaço) e as representações espaciais (os significados, os símbolos, a imaginação, a invenção, os modo de ver, sentir e "provar" o espaço), que constroem o sentimento e o significado de pertencimento dos grupos ou indivíduos em relação a um território, isto é, são e re-produzem constantemente o território.

A identidade territorial, tal qual propõem o autor, aciona-se em espaços e tempos, geografias e histórias para produzir e moldar uma mobilização e consentimento, de modo que os sujeitos de um determinado recorte espacial, de um território, se re-conheçam, em alguma medida, como participantes de um espaço-tempo e de uma "sociedade comum". Cria-se, portanto, uma consciência sócio-espacial de pertencimento; é o sentido de pertença, os laços de solidariedade e de unidade que constituem os sentimentos de reconhecimento com indivíduos e/ou grupo social em relação a uma comunidade, a um lugar, a um território. Essa consciência identitária não é natural ou essencial, é uma construção simbólica-política e estratégicaposicional-discursiva. Constroem-se através de representações espaciais que envolvem, concomitantemente, o domínio funcional-estratégico sobre um demarcado espaço (através de finalidades) e a apropriação simbólico/expressiva do espaço (através de afetividades).

Haesbaert (2007) ressalta, também, que a identificação é um processo espacial. A identificação está ligada ao identificar-se com uma pessoa, com um lugar, com um território. Identificar-se, assim, se desdobra com e a partir da dimensão espacial; identificar-se produz também comparações e classificações; identificar-se com um território pressupõe não se identificar com 
outro território, o que, pressupõe, novamente, comparações, classificações etc., que são construídas através de disputas e, portanto, de relações de poder. Assim, "se identificar(-se) é também, de alguma forma, classificar, estas classificações com que re-significamos o mundo, nós e os outros", inclusive através dos territórios, "são objeto de intensas disputadas entre aqueles que têm o poder de formular e mesmo de fixar estas classificações" (p. 37).

Por isso, para Haesbaert (2006), toda relação de poder espacialmente medida é também produtora de identidade, pois controla, distingue, classifica, exclui, separa e, ao separar, de alguma forma nomeia, classifica (e, portanto, exclui) os indivíduos e os grupos sociais das relações, dos territórios. Por outro lado, todo processo de identificação social é também uma relação política, acionada como (geo)estratégia em momentos de conflito e/ou negociação. Desse modo, a identidade busca construir um "cimento entre as classes" podendo produzir tanto a dominação quanto à resistência.

\section{Identidades territoriais: processo, construção e invenção do "sujeito- territorial"}

Assim, em função dessas considerações sistematizadas a partir de alguns autores, compreendemos que a identidade é construída tanto geográfica quanto historicamente pelas relações sociais. Envolve, concomitantemente, a dimensão espacial, material e simbólica da realidade praticada, vivida. Assim, a identidade é aberta, é múltipla, é relacional, é uma construção (um constructo), um efeito mobilizador, um processo de produção, um ato performático e político, discursivo e narrativo que pode produzir consentimento e ação. A identidade é instável, contraditória, "inconsistente", inacabada. A identidade está ligada às representações: classificações, divisões, comparações, exclusões e nomeações. E, por tudo isso, está estreitamente conectada, impregnada e prenhe de conflitos, de disputas, de divisões, de ações, do (con)sentimento, da mobilização, do silenciar, do legitimar, do exaltar/enaltecer ao esconder/dissimular, da dominância e da resistência, isto é, de profundas relações de poder. 
Nesse sentido, segundo Mendes (2005, p. 534), na análise da construção cultural e política da identidade, "não é de esperar que o analista saia incólume, mas espera-se um esforço de apresentação das diferentes perspectivas, numa contribuição modesta para o sublinhar da humanidade que habita em todos nós". E, com isso, concordamos com Boaventura de Sousa Santos (1997, p. 30), quando afirma que "as pessoas e os grupos sociais têm o direito a ser iguais quando a diferença os inferioriza, e o direito a ser diferentes, quando a igualdade os descaracteriza".

\footnotetext{
${ }^{1}$ Para Hall (2004), a nação seria "construída" pela narrativa enquanto "comunidade imaginada". Essa comunidade imaginada seria forjada a partir de um discurso do qual narra a nação homogênea, negando, na maioria das vezes a diversidade e, com isso, outras formas de ser e fazer que não a "idealizada" pela nação. Nesse sentido, para o autor "as culturas nacionais são compostas não apenas de instituições culturais, mas também de símbolos e representações. Uma cultura nacional é um discurso - um modo de construir sentidos que influencia e organiza tanto nossas ações quanto a concepção que temos de nós mesmos (...). As culturas nacionais, ao produzir sentidos sobre 'a nação', sentidos com os quais podemos nos identificar, constroem identidades [leia-se forjam identidades]. Esses sentidos estão contidos nas estórias que são contadas sobre a nação, memórias que conectam seu presente com seu passado e imagens que dela são construídas" (pp. 50-51, [grifos do autor]).

${ }^{2}$ Segundo Pierre Bourdieu (1998, p. 4), "(...) a dinâmica da distinção social não se esgota no conflito simbólico pela imposição de uma dada representação da sociedade, mas prolonga-se na produção incessante de novos gostos socialmente diferenciadores e no abandono progressivo das práticas culturais entretanto aplicado pelas camadas subalternas".

${ }^{3}$ De acordo com Mendes (2005, p. 323), "A subjetividade, o self, não é um corpo isolado, mas encontrase sim distribuído em diferentes materialidades e práticas. E, mais importante, cada pessoa não é uma fortaleza, mas sim algo que ganha em ter fronteiras permeáveis de forma a ser ajudado por outro. A subjetividade e a corporalidade são ativadas e constituídas numa variedade de formas e processos. As identidades não são essências desencarnadas, mas teias complexas de relações, materiais e desejos".

${ }^{4} \dot{E}$ interessante ressaltar, que esse compartilhamento de experiências se deve a um compartilhamento territorial, ou seja, a uma relação estabelecida "univocamente" entre as experiências dos indivíduos e uma parcela referencial e mediadora do espaço.

${ }^{5}$ Ainda, segundo Halbwachs (2006, p. 102), a memória coletiva "é uma corrente de pensamento contínuo, de uma continuidade que nada tem de artificial, pois não retém o passado senão o que ainda está vivo ou é capaz de viver na consciência do grupo. Por definição, não ultrapassa os limites desse grupo" $E$, também, "Na realidade, existe muitas memórias coletivas". Para Oliven (1992, p. 20), "A memória coletiva está ligada a um grupo relativamente restrito e portador de uma tradição, aproximando-se do mito e manifestando-se através da ritualização dessa tradição. Já a memória nacional refere-se a uma entidade mais ampla e genérica (a nação), aproximando-se mais da ideologia e, por conseguinte, estendendo-se à sociedade como um todo e definindo-se como universal".
}

\section{Referências}

BAUMAM, Zygmunt. Identidade. Rio de Janeiro: Jorge Zahar, 2005. BHABHA, Homi K. O local da cultura. Belo Horizonte: Ed. UFMG, 1998. BOURDIEU, Pierre. O poder simbólico. 2. ed. Lisboa; Rio de Janeiro: Bertrand Brasil, 1998. 
CASTELLS, Manuel. A sociedade em rede. 6 ed. São Paulo: Paz e terra, $1999 b$.

. O poder da identidade. 3. ed. São Paulo: Paz e Terra, 1999a.

CHAUÍ, Marilena. Brasil: Mito fundador e sociedade autoritária. São Paulo, Perseu Abramo, 2006.

DAMATTA, Roberto. Nação e região: em torno do significado cultural de uma permanente dualidade brasileira. SCHULER, F. L.; BORDINI, M. da G. (Orgs.). Cultura e identidade regional. Porto Alegre: EDIPUCRS, 2004, pp. 21-36.

FOUCAULT, Michel. Microfísica do poder. 5 ed. Rio de Janeiro: Graal, 1985.

HAESBAERT, Rogério \& BÁRBARA, Marcelo de Jesus Santa. Identidade e Migração em áreas Transfronteiriças. Geographia, Niterói, v. 5, pp. 45-65, 2001 a.

. Identidades territoriais. In: ROSENDHAL, Z. CORREA, R. (Orgs.). Manifestações da cultura no espaço. Rio de Janeiro: EdUERJ, 1999, pp. 169190.

Identidades territoriais: entre a multiterritorialidade e a reclusão territorial (ou: do hibridismo cultural à essencialização das identidades). In: ARAUJO, F. G. de. HAESBAERT, R. (Org.). Identidade territórios: questões e olhares contemporâneos. Rio de Janeiro: Access, 2007, pp. 33-56.

Identidades territoriais: entre a multiterritorialidade e a reclusão territorial (ou: do hibridismo cultural à essencialização das identidades). In: ARAUJO, F. G. de. HAESBAERT, R. (Org.). Identidade territórios: questões e olhares contemporâneos. Rio de Janeiro: Access, 2007, pp. 33-56.

O Mito da Desterritorialização: do "Fim dos Territórios" à Multiterritorialidade. 2. ed. Rio de Janeiro: Bertrand Brasil, 2006.

HALBWACHS, Maurice. A Memória Coletiva. São Paulo: Centauro, 2006.

HALL, Stuart. A identidade cultural na pós-modernidade. 9. ed. Rio de Janeiro: DP\&A, 2004.

. Da diáspora: identidades e mediações culturais. Organização Liv Sovik. Belo Horizonte: EdUFMG; Brasília: Representação da UNESCO no Brasil, 2003.

Quem precisa da identidade? In. SILVA, Tomaz Tadeu da (Org.). Identidade e diferença: a perspectiva dos estudos culturais. Petrópolis, RJ: Vozes, 2007. pp. 103-133.

HARVEY, David. Condição pós-moderna. Uma pesquisa sobre as origens da mudança cultural. São Paulo: Edições Loyola, 1994.

HOBSBAWM, Eric. Introdução: A invenção das tradições. HOBSBAWM, Eric. RANGER, Terencer. (Org.). A invenção das tradições. Rio de Janeiro: Paz e Terra, 1997, pp. 9-24.

. RANGER, Terencer. (Org.). A invenção das tradições. Rio de Janeiro:

Paz e Terra, 1997.

MENDES, José Manuel Oliveira. O. O desafio das identidades. In: SOUSA SANTOS, Boaventura de (Org.). A globalização e as ciências sociais. 3 ed. São Paulo: Cortez, 2005, p. 503-540.

MOREIRA, Ruy. A diferença e a geografia: o ardil da identidade e a representação da diferença na geografia. GEOgraphia. Revista do Departamento de Geografia da UFF, Niterói: ano I - n 1, 1999. 
OLIVEN, Ruben George. A parte e o todo: a diversidade cultural no Brasil-Nação. Petrópolis: Vozes, 1992.

POLLAK, Michel. Memória e identidade social. Estudos Históricos. Rio de Janeiro: Cpdoc/FGV, vol.5, n. 10, p. 200-215, 1992.

SILVA, Tomaz Tadeu da. A produção social da identidade e da diferença. In. SILVA, Tomaz Tadeu da (Org.). Identidade e diferença: a perspectiva dos estudos culturais. Petrópolis, RJ: Vozes, 2007. pp. 73-102.

SOUSA SANTOS, Boaventura de. Por uma concepção multicultural de direitos humanos. Revista Crítica de Ciências Sociais. Porto. n. 48. v. 1. p.11-32, 1997. Território, Cultura e Des-territorialização. In: ROSENDHAL, Z. CORREA, R. (Orgs.). Religião, identidade e território. Rio de Janeiro: EdUERJ, 2001b, pp. 115-144.

WOODWARD, Kaathryn. Identidade e diferença: uma introdução teórica e conceitual. In. SILVA, Tomaz Tadeu da (Org.). Identidade e diferença: a perspectiva dos estudos culturais. Petrópolis, RJ: Vozes, 2007. pp. 7-72.

Artigo encaminhado para publicação em maio de 2009.

Artigo aceito para publicação em julho de 2009. 